\title{
The Vaporization Enthalpy and Vapor Pressure of $( \pm) N$-Ethyl Amphetamine by Correlation Gas Chromatography
}

\author{
James S. Chickos
}

check for

updates

Citation: Chickos, J.S. The Vaporization Enthalpy and Vapor Pressure of $( \pm) N$-Ethyl

Amphetamine by Correlation Gas Chromatography. Molecules 2021, 26 , 3809. https://doi.org/10.3390/ molecules26133809

Academic Editors: Vera L. S. Freitas, Maria Ribeiro da Silva and

Vladislav Tomisic

Received: 19 May 2021

Accepted: 16 June 2021

Published: 22 June 2021

Publisher's Note: MDPI stays neutral with regard to jurisdictional claims in published maps and institutional affiliations.

Copyright: (C) 2021 by the author. Licensee MDPI, Basel, Switzerland. This article is an open access article distributed under the terms and conditions of the Creative Commons Attribution (CC BY) license (https:/ / creativecommons.org/licenses/by/ $4.0 /)$.
Department of Chemistry and Biochemistry, University of Missouri-St. Louis, 1 University Blvd, St. Louis, MO 63121, USA; jsc@umsl.edu Tel.: +1-314-5165377

\begin{abstract}
The vaporization enthalpy, and vapor pressure as a function of temperature of $N$-ethylamphetamine, a substance used in the 1950s as an appetite suppressant and more currently abused as a designer drug, is reported. Its physical properties are compared to those of $\mathrm{S}(+)-N$-methamphetamine, a substance whose physiological properties it mimics. A vaporization enthalpy of $(62.4 \pm 4.4) \mathrm{kJ} \cdot \mathrm{mol}^{-1}$ and vapor pressure of $(19 \pm 11) \mathrm{Pa}$ at $T=298.15 \mathrm{~K}$ has been evaluated by correlation gas chromatography. Results are compared to estimated values and to the limited amount of experimental property data available.
\end{abstract}

Keywords: $N$-ethylamphetamine; S (+)-methamphetamine; vaporization enthalpy; vapor pressure; correlation gas chromatography

\section{Introduction}

$\mathrm{N}$-Ethyl amphetamine, also known as etilamfetamine, marketed as the hydrochloride salt under the trade name, Apetinil ${ }^{\mathrm{TM}}$, was sold as an appetite suppressant in the 1950s [1]. It has been abused as a recreational stimulant, a "designer drug" alternative to amphetamine and possibly (+) S-methamphetamine [2]. Unlike R (-) N-methamphetamine, which is available over the counter as a nasal decongestant [3], and (+) S-methamphetamine, a DEA Schedule I controlled substance, $\mathrm{N}$-ethyl amphetamine, also a DEA Schedule I controlled substance, was sold as the racemic material [2]. Substances with this classification have no current accepted medical use [1]. N-ethyl amphetamine is metabolized to amphetamine or excreted unchanged. Of the two enantiomers, the $(+)$ enantiomer is metabolized to a greater extent [4]. The racemate has been available commercially in small quantities for analytical purposes.

Despite the use and abuse of this drug, very little information is available about its properties, presumably because of the restrictions regarding its accessibility. Our laboratory has been investigating the use of a technique referred to a correlation gas chromatography to evaluate both vaporization enthalpies and vapor pressures of materials that are either difficult to access, or beyond the current capabilities of most conventional techniques used for these purposes. This includes substances that are present in complex mixtures [5,6], are either quite non-volatile [7], or as in this case, available only in very small quantities [8]. This work describes our results for $( \pm) \mathrm{N}$-ethylamphetamine whose structure is given in Figure 1 along with the materials used as standards. 
<smiles>CN[C@@H](C)Cc1ccccc1</smiles>

$\left(\mathrm{CH}_{3} \mathrm{CH}_{2} \mathrm{CH}_{2} \mathrm{CH}_{2}\right) \mathrm{NH}$<smiles>CCCCCCN</smiles><smiles>CCNC(C)Cc1ccccc1</smiles><smiles>NC1CCNCC1Cc1ccccc1</smiles>

Figure 1. Left to right: $(d l) \mathrm{S}(+)$-methamphetamine, $(d l)$-N-ethylamphetamine, 4-benzylpiperidine; $\mathrm{N}, \mathrm{N}$-dibutylamine, $\mathrm{N}, \mathrm{N}$-dipentylamine; $\mathrm{N}, \mathrm{N}$-dihexylamine, $\mathrm{N}, \mathrm{N}$-diheptylamine.

\section{Experimental Methods}

The origin of the materials used, their CAS numbers and their composition in mass fraction are provided in Table 1. Two of the materials were also analyzed by gas chromatography. Analysis of the remaining compounds were provided by their suppliers. The solvent used was methanol. A methanolic solution of the standards were prepared by dissolving a drop of each into a small vial containing $1 \mathrm{~mL}$ of methanol and adding several drops of this solution to approximately a $0.5 \mathrm{~mL}$ of the methanolic solution of (dl)-N-ethylamphetamine until comparable amounts of standards and target were achieved; composition was monitored by gas chromatography. Each compound in the mixture was identified independently by its retention time.

Table 1. Origin of the standards and $d$-methamphetamine and their analysis.

\begin{tabular}{cccc}
\hline Compound & CAS Registry No. & Supplier & Mass Fraction Supplier \\
\hline Methanol & $67-56-1$ & Fisher Scientific & 0.998 \\
N,N-Dibutylamine & $111-92-2$ & Aldrich & 0.99 \\
$(d l)$ - N-Ethylamphetamine & $457-87-4$ & Millipore Sigma & reference standard \\
N,N-Dipentylamine & $2050-92-2$ & TCI & $>0.97$ \\
4-Benzylpiperidine & $31252-42-3$ & Aldrich & 0.99 \\
N,N-Dihexylamine & $143-16-8$ & TCI & $>0.991$ \\
N,N-Diheptylamine & $2470-68-0$ & TCI & $>0.98$ \\
\hline
\end{tabular}

${ }^{1}$ Available in a sealed ampule in methanol, $(1 \mathrm{mg} / \mathrm{mL})$.

\subsection{Analytical Methods}

An HP 5890 gas chromatograph running HP Chemstation and equipped with a $15 \mathrm{~m}$ Supelco SPB- 5 capillary column $(0.32 \mathrm{~mm}, 1.0 \mu \mathrm{m}$ film thickness $)$ at a split ratio of approximately $80 / 1$ was used for the analysis and the measurements. Helium was used as the carrier gas at a head pressure of approximately $150 \mathrm{kPa}$. Column temperature was controlled by the instrument to $( \pm 0.1) \mathrm{K}$ as monitored by a high temperature probe connected to a Go Link ${ }^{\mathrm{TM}}$ interface. At the temperatures of the experiments, methanol is not retained by the column as evidenced by a slight increase in its retention time with temperature. This increase is due to the increase in viscosity of the carrier gas with temperature and serves as a measure of the flow through the column. Isothermal chromatograms were recorded at $T=5 \mathrm{~K}$ intervals over a $30 \mathrm{~K}$ temperature range. All retention times recorded are provided in the Supplementary Materials, Table S1-S3.

\subsection{Thermochemical Methods: Vaporization Enthalpies}

A basic premise in correlation gas chromatography, is that the time an analyte spends on the column, its resident time, $t_{\mathrm{r}}$, is inversely proportional to its vapor pressure $p$, off the column. If $1 / t_{\mathrm{r}}$ is proportional to to $p$, then $\ln \left(1 / t_{\mathrm{r}}\right)$ can be related to $\mathrm{K} / T$, by the Clausius Clapeyron relationship. Residence times can be evaluated by the difference 
in retention times of the analyte and a non-retained reference, in this case, methanol. Plots of $\ln \left(t_{\mathrm{o}} / t_{\mathrm{r}}\right)$ vs $\mathrm{K} / \mathrm{T}$, where $t_{\mathrm{o}}$ is the reference time, $60 \mathrm{~s}$, results in a linear relationship, the slope of which is related to an enthalpy when multiplied by the gas constant, $-R\left(8.314 \mathrm{~J} \cdot \mathrm{mol}^{-1} \cdot \mathrm{K}^{-1}\right)$. This enthalpy, $\Delta_{t r n}^{g} H_{m}\left(T_{m}\right)$, is related to the vaporization enthalpy by Equation (1), where $\Delta_{l}^{g} H_{m}\left(T_{m}\right)$ refers to the vaporization enthalpy and $\Delta H_{\text {intr }}\left(T_{m}\right)$ is a measure of the interaction of each analyte with the column [9]. The term, $\Delta_{t r n}^{g} H_{m}\left(T_{m}\right)$, is referred to as the enthalpy of transfer of the analyte from the stationary phase of the column to the gas phase. The non-retained reference is identified by its temperature dependence of $t_{\mathrm{r}}$, which contrary to retained substances, actually increases slightly with temperature due to the slight increase in viscosity of the carrier gas.

$$
\Delta_{t r n}^{g} H_{m}\left(T_{m}\right)=\Delta_{l}^{g} H_{m}\left(T_{m}\right)+\Delta H_{\text {intr }}\left(T_{m}\right)
$$

When materials similar to the target (s) with known vaporization enthalpies are included in the chromatography, a plot of $\Delta_{l}^{g} H_{m}(298.15 \mathrm{~K})$ vs. $\Delta_{t r n}^{g} H_{m}\left(T_{m}\right)$ is linear. The slope and intercept of the line together with the value of $\Delta_{t r n}^{g} H_{m}\left(T_{m}\right)$ of the target can be used to evaluate $\Delta_{l}^{g} H_{m}(298.15 \mathrm{~K})$ of the target. The structure of the hydrocarbon portion of the standards may vary as long as the number and type of functional groups present in the targets are matched. Best results are obtained with homologous series $[10,11]$.

\subsection{Thermochemical Methods: Vapor Pressures}

The relationship between $t_{\mathrm{o}} / t_{\mathrm{r}}$ and the vapor pressure of the material off the column also suggests a possible relationship between $t_{\mathrm{o}} / t_{\mathrm{r}}$ and $p$, the vapor pressure of the pure material, provided appropriate standards are chosen functionally related to the target (s). We have found that a plot of $\ln \left(p / p^{\circ}\right)$ against $\ln \left(t_{\mathrm{o}} / t_{\mathrm{r}}\right)$, where $p^{\mathrm{o}}$ is a reference pressure, in this work $101,325 \mathrm{~Pa}$, a linear relationship is obtained which frequently persists over a range of temperatures. The parameters of this relationship together with the values of $\ln \left(t_{\mathrm{o}} / t_{\mathrm{r}}\right)$ of the target (s) can afford the vapor pressure (s) of the targets in a fashion similar to what has been described above. As with vaporization enthalpy, the quality of the results are depended on the similarity between standards and targets and the quality of the properties that are being correlated.

\subsection{Uncertainties}

All uncertainties reported in this work refer to one standard deviation unless noted otherwise [12]. Linear and non-linear least squares were performed by Excel and Sigma Plot 14, respectively. All regression coefficients $\left(\mathrm{r}^{2}\right)$ not described below exceeded 0.99 . Uncertainties obtain from logarithmic relationships are reported as an average value. The uncertainties reported are generally a measure of the quality of the correlation; actual uncertainties in the values reported may vary. Evaluation of the uncertainty in the reported boiling temperature is described below. Whenever possible, uncertainties in combined results are evaluated as the square root of the sum of the squares of the uncertainty of each contributing term.

\subsection{Estimation of Vaporization Enthalpy}

An estimate of the potential vaporization enthalpy is quite helpful in identifying either unanticipated interactions [13] or unreasonable experimental results. A very simple yet quite useful equation for evaluating relatively simple molecules is given by Equation (2) [14]. The terms $n_{C}$ in Equation (2) defines the total number of carbon atoms and and $n_{\mathrm{Q}}$, the number of quaternary $\mathrm{sp}^{3}$ hybridized carbon atoms, respectively. The $\mathrm{b}$ term identifies the contribution of the functional group, for a secondary amine, $\mathrm{b}=8.9 \mathrm{~kJ} \cdot \mathrm{mol}^{-1}$ and the $\mathrm{C}$ term for compounds containing a single functional group corrects for each carbon branch off an $\mathrm{sp}^{3}$ hybridized carbon present, $\mathrm{C}=-2.0 \mathrm{~kJ} \cdot \mathrm{mol}^{-1} \cdot$ branch $^{-1}$. For $\mathrm{N}$ ethylamphetamine, $n_{\mathrm{C}}=11, n_{\mathrm{Q}}=0$, and there are no carbon branches on an $\mathrm{sp}^{3}$ hybridized 
carbon atom resulting in a vaporization enthalpy at $T=298.15 \mathrm{~K}$ of $(63.5 \pm 3.2) \mathrm{kJ} \cdot \mathrm{mol}^{-1}$. The uncertainty associated with the estimation is general $5 \%$ of the value estimated.

$$
\Delta_{l}^{g} H_{m}(298.15 \mathrm{~K}) / \mathrm{kJ} \cdot \mathrm{mol}^{-1}=4.69\left(n_{c}-n_{Q}\right)+1.3 n_{Q}+\mathrm{b}+3.0+\mathrm{C}
$$

\subsection{Vaporization Enthalpy: Temperature Adjustments}

Vaporization enthalpies of the standards are summarized in Table 2. Not all are available at $T=298.15 \mathrm{~K}$. Temperature adjustments for those reported at different temperatures have been adjusted to $T=298.15 \mathrm{~K}$ according to Equation (3). Heat capacities for these adjustments were evaluated by group additivity using the protocol summarized in Reference [15]. For compounds with more than one vaporization enthalpy cited, an average value was used in subsequent correlations.

$$
\begin{gathered}
\Delta_{1}^{g} H_{m}(298.15 \mathrm{~K}) / \mathrm{kJ} \cdot \mathrm{mol}^{-1}=\Delta_{1}^{g} H_{m}\left(T_{m}\right) / \mathrm{kJ} \cdot \mathrm{mol}^{-1}+ \\
{\left[\left(10.58+0.26 \cdot C_{\mathrm{p}}(\mathrm{l}, 298 \mathrm{~K}) /\left(\mathrm{J} \cdot \mathrm{mol}^{-1} \cdot \mathrm{K}^{-1}\right)\right)\left(T_{m} / \mathrm{K}-298.15 \mathrm{~K}\right)\right] / 1000}
\end{gathered}
$$

\begin{tabular}{|c|c|c|c|c|c|c|}
\hline & $\begin{array}{c}\Delta_{l}^{g} H_{m}\left(T_{m}\right) \\
\mathbf{k J} \cdot \mathbf{m o l}^{-1}\end{array}$ & $T_{\mathrm{m}} / \mathrm{K}$ & $\begin{array}{l}C_{\mathrm{p}}(1,298 \mathrm{~K})^{1} \\
\mathrm{~J} \cdot \mathrm{mol}^{-1} \cdot \mathrm{K}^{-1}\end{array}$ & $\begin{array}{l}\Delta C_{\mathrm{p}} \Delta T^{2} \\
\mathrm{~kJ} \cdot \mathrm{mol}^{-1}\end{array}$ & $\begin{array}{c}\Delta_{l}^{g} H_{m}(298 \mathrm{~K}) \\
\mathrm{kJ} \cdot \mathrm{mol}^{-1}\end{array}$ & Ref. \\
\hline \multirow[t]{4}{*}{ N,N-Dibutylamine } & $50.8 \pm 4.1$ & 298.15 & 308.2 & & $50.8 \pm 4.1$ & [8] \\
\hline & 46.0 & 343.2 & 308.2 & $4.1 \pm 1.0$ & $50.1 \pm 1.0$ & [16] \\
\hline & 44.75 & 358.2 & 308.2 & $5.4 \pm 1.0$ & $50.2 \pm 1.0$ & [16] \\
\hline & $49.4 \pm 0.1$ & 298.15 & 308.2 & & $49.4 \pm 0.1$ & [17] \\
\hline Average & & & & & $50.1 \pm 0.6^{3}$ & \\
\hline \multirow[t]{2}{*}{ N,N-Dipentylamine } & $61.2 \pm 2.6$ & 298.15 & 372 & & $61.2 \pm 2.6$ & [8] \\
\hline & 51.2 & 394 & 372 & $10.3 \pm 1.6$ & $61.4 \pm 1.6$ & [18] \\
\hline Average & & & & & $61.3 \pm 2.1^{3}$ & \\
\hline \multirow[t]{2}{*}{ N,N-Dihexylamine } & $70.8 \pm 4.7$ & 298.15 & 435.8 & & $70.8 \pm 4.7$ & [8] \\
\hline & 55.1 & 423 & 435.8 & $15.5 \pm 2.1$ & $70.5 \pm 2.1$ & {$[17,18]$} \\
\hline Average & & & & & $70.7 \pm 3.4^{3}$ & \\
\hline 4-Benzylpiperidine & $74.2 \pm 1.0$ & 298 & & & $74.2 \pm 1.0$ & [19] \\
\hline \multirow[t]{2}{*}{ N,N-Diheptylamine } & 60.0 & 450 & 499.6 & $21.3 \pm 2.6$ & $81.3 \pm 2.6$ & [18] \\
\hline & $81.2 \pm 7.1$ & 298.15 & 499.6 & & $81.2 \pm 7.1$ & [8] \\
\hline Average & & & & & $81.3 \pm 4.9^{3}$ & \\
\hline
\end{tabular}

Table 2. Temperature adjustments of literature vaporization enthalpies.

${ }^{1}$ Heat capacities evaluated by group additivity [14]; no experimental heat capacities were located in Reference [20]. ${ }^{2}$ Temperature adjustments were evaluated using the following equation for liquids [15]. ${ }^{3}$ One standard deviation $( \pm 1 \sigma)$ associated with the values cited.

\subsection{Vapor Pressures}

Vapor pressures of the $\mathrm{N}, \mathrm{N}$-dialkylamines are all available in the form of the Antoine equation, Equation (4). Table 3 lists the constants of this equation and the temperature range at which these constants are applicable. The vapor pressures of 4-benzylpiperidine, listed at the bottom of the table, are expressed in the form of a third order polynomial, Equation (4). The constants of this polynomial are also provided. As indicated in the table, only one set of Antoine constants are applicable at ambient temperatures. We have previously observed however, that the vapor pressures generated by these constants, correlated quite well as a function of temperature [8]. With the exception of 4-benzylpiperidine, all amines are members of a homologous series. Since the vapor pressures of the first member of the series is valid over a broad range of temperatures, the quality of the correlations as 
a function of temperature suggests that vapor pressures resulting from extrapolations of the remaining members are relatively reliable.

$$
\begin{gathered}
\text { Antoine Equation } \ln (p / \mathrm{kPa})=\mathrm{A}_{\mathrm{A}}-\mathrm{B}_{\mathrm{A}} /\left(\mathrm{T} / \mathrm{K}+\mathrm{C}_{\mathrm{A}}\right) \\
\ln \left(p / p^{\mathrm{o}}\right)=\mathrm{A}_{\mathrm{T}}+\mathrm{B}_{\mathrm{T}}(\mathrm{T} / \mathrm{K})+\mathrm{C}_{\mathrm{T}}(\mathrm{T} / \mathrm{K})^{2}+\mathrm{D}_{\mathrm{T}}(T / \mathrm{K})^{3} ; p^{\mathrm{o}}=101,325 \mathrm{~Pa}
\end{gathered}
$$

\begin{tabular}{|c|c|c|c|c|c|c|}
\hline Antoine Equation (4) & $\mathbf{A}_{\mathrm{A}}$ & $\mathbf{B}_{\mathbf{A}}$ & $-\mathrm{C}_{\mathrm{A}}$ & $T_{\text {range }} / \mathrm{K}$ & $p_{(1,298 \mathrm{~K})} / \mathrm{Pa}$ & Ref. \\
\hline $\mathrm{N}, \mathrm{N}$-Dibutylamine & 14.6511 & 3687.84 & 65.37 & $286-371$ & 304 & [16] \\
\hline $\mathrm{N}, \mathrm{N}$-Dipentylamine & 14.7935 & 4105.74 & 72.15 & $379-527$ & 34 & [18] \\
\hline $\mathrm{N}, \mathrm{N}$-Dihexylamine & 15.1013 & 4635.56 & 69.15 & $408-569$ & 5.8 & [18] \\
\hline$N, N$-Diheptylamine & 14.8948 & 4716.85 & 86.15 & $435-605$ & 0.64 & [18] \\
\hline $\begin{array}{c}\text { 3rd Order Polynomial } \\
\text { Equation (5) }\end{array}$ & $\mathbf{A}_{T}$ & $\mathbf{B}_{\mathrm{T}}$ & $\mathrm{C}_{\mathrm{T}} \times 10^{-4}$ & $\mathrm{D}_{\mathrm{T}} \times 10^{-6}$ & $p_{(\mathbf{1}, 298 \mathrm{~K})} / \mathrm{Pa}$ & \\
\hline 4-Benzylpiperidine & 6.74 & -1642.3 & -130.851 & 62.508 & 1.5 & [8] \\
\hline (S) (+)-Methamphetamine & 7.592 & -2119.6 & -84.929 & 31.824 & 39 & [8] \\
\hline
\end{tabular}

Table 3. Constants for the Antoine equation (and of a third order polynomial; $p^{o}=101,325 \mathrm{~Pa}$ ).

\section{Results}

\subsection{Vaporization Enthalpies}

Plots of $\ln \left(t_{\mathrm{o}} / t_{\mathrm{r}}\right)$ vs. $\mathrm{K} / \mathrm{T}$ of each analyte at $5 \mathrm{~K}$ intervals over a $30 \mathrm{~K}$ temperature range were linear, characterized by correlation coefficients $r^{2}>0.999$. Enthalpies of transfer were calculated as the product of the absolute value of the slope of the line and the gas constant. Vaporization enthalpies of the standards plotted against the enthalpies of transfer were also linear. Vaporization enthalpy of the target was calculated as the sum of the product of the slope of the line and the enthalpy of transfer and the intercept, Equation (6). Table 4 summarizes the results of one of two duplicate runs. Results of the second run are reported in the SM. Results for both runs are summarized in Table 5 and are discussed below.

\begin{tabular}{|c|c|c|c|c|c|}
\hline \multirow{2}{*}{ Run 1} & \multirow{2}{*}{$\begin{array}{c}\text {-Slope } \\
\text { T/K }\end{array}$} & \multirow{2}{*}{ Intercept } & \multirow{2}{*}{$\begin{array}{c}\Delta_{t r n}^{g} H_{m}(408 \mathrm{~K}) \\
\mathrm{kJ} \cdot \mathrm{mol}^{-1}\end{array}$} & \multicolumn{2}{|c|}{$\Delta_{l}^{g} H_{m}(298.15 \mathrm{~K}) / \mathrm{kJ} \cdot \mathrm{mol}^{-1}$} \\
\hline & & & & (lit) $^{2}$ & (calc) \\
\hline$N, N$-Di-n-butylamine & $4197.2 \pm 20$ & $10.984 \pm 0.05$ & $34.89 \pm 0.16$ & $50.1 \pm 0.6$ & $50.4 \pm 3.4$ \\
\hline$N, N$-Di-n-pentylamine & $5121.3 \pm 23$ & $12.181 \pm 0.06$ & $42.58 \pm 0.19$ & $61.3 \pm 2.1$ & $61.0 \pm 3.7$ \\
\hline$N$-Ethylamphetamine & $5238.1 \pm 24$ & $11.973 \pm 0.06$ & $43.55 \pm 0.20$ & & $62.4 \pm 3.8$ \\
\hline$N, N$-Di-n-hexylamine & $6037.1 \pm 24$ & $13.374 \pm 0.06$ & $50.19 \pm 0.20$ & $70.7 \pm 3.4$ & $71.5 \pm 4.0$ \\
\hline 4-Benzylpiperidine & $6149.2 \pm 27$ & $12.810 \pm 0.07$ & $51.12 \pm 0.22$ & $74.2 \pm 1.0$ & $72.8 \pm 4.1$ \\
\hline$N, N$-Di-n-heptylamine & $6937.5 \pm 36$ & $14.546 \pm 0.09$ & $57.68 \pm 0.30$ & $81.3 \pm 4.9$ & $81.8 \pm 4.3$ \\
\hline \multicolumn{4}{|c|}{$\Delta_{l}^{g} H_{m}(298.15 \mathrm{~K}) / \mathrm{kJ} \cdot \mathrm{mol}^{-1}=(1.38 \pm 0.06) \Delta_{t r n}^{g} H_{m}(408 \mathrm{~K})+(2.3 \pm 2.8)$} & \multicolumn{2}{|l|}{$r^{2}=0.9947(6)$} \\
\hline
\end{tabular}

Table 4. Correlation between $\Delta_{l}^{g} H_{m}(298.15 \mathrm{~K})$ and $\Delta_{t r n}^{g} H_{m}(408 \mathrm{~K})$ of the standards ${ }^{1}$. 
Table 5. Summary: Vaporization Enthalpy $\left(\mathrm{kJ} \cdot \mathrm{mol}^{-1}\right)$ at $T=298.15 \mathrm{~K}^{1}$.

\begin{tabular}{cccccc}
\hline & Run 1 & Run 2 & Average & Lit. $^{2}$ & Estimate \\
\hline N,N-Di-n-butylamine & $50.4 \pm 3.4$ & $50.2 \pm 4.5$ & $50.3 \pm 4.0$ & $50.1 \pm 0.6^{3}$ & $49.4 \pm 2.4$ \\
N,N-Di-n-pentylamine & $61.0 \pm 3.7$ & $60.9 \pm 4.9$ & $61.0 \pm 4.3$ & $61.3 \pm 2.1^{4}$ & $58.8 \pm 2.9$ \\
N-Ethylamphetamine & $62.4 \pm 3.8$ & $62.3 \pm 4.9$ & $62.4 \pm 4.4$ & $63.5 \pm 3.2$ \\
N,N-Di-n-hexylamine & $71.5 \pm 4.0$ & $71.8 \pm 5.3$ & $71.7 \pm 4.7$ & $70.7 \pm 3.4^{4}$ & $68.2 \pm 3.4$ \\
4-Benzylpiperidine & $72.8 \pm 4.1$ & $73.3 \pm 5.4$ & $73.1 \pm 4.8$ & $74.2 \pm 1.0^{5}$ & $68.2 \pm 3.4$ \\
N,N-Di-n-heptylamine & $81.8 \pm 4.3$ & $82.5 \pm 5.8$ & $82.2 \pm 5.1$ & $81.3 \pm 4.9^{4}$ & $77.6 \pm 3.9$ \\
\hline
\end{tabular}

${ }^{1}$ Uncertainties represent one standard deviation. ${ }^{2}$ See Table 2 for details. ${ }^{3}$ Average from References [8,16,17]. ${ }^{4}$ Average from References $[8,18] .{ }^{5}$ Reference [19].

\subsection{Vapor Pressures}

With the exception on 4-benzypiperidine, the vapor pressures of all other standards are available in the form of the Antoine equation. Vapor pressures calculated using Equation (4) were first converted to Pa and then correlated in the form $\ln \left(p / p^{\circ}\right)$ where $p^{\mathrm{O}}$ refers to 101,325 Pa. Runs 1 and 2 were both performed under similar experimental conditions. Values of $t_{\mathrm{o}} / t_{\mathrm{r}}$ of each respective analyte, calculated from the slopes and intercepts of Tables S2 and S4 (see Supplementary Materials) were averaged, and then $\ln \left(p / p^{\circ}\right)$ of the standards were correlated against their respective $\ln \left(t_{\mathrm{o}} / t_{\mathrm{r}}\right)$ avg values at $T=(298.15,310)$ $\mathrm{K}$ and at $10 \mathrm{~K}$ increments up to $450 \mathrm{~K}$; the correlations also included 4-benzypiperidine. The resulting correlation equation at each temperature together with $\ln \left(t_{\mathrm{o}} / t_{\mathrm{r}}\right)_{\text {avg }}$ of $\mathrm{N}$ ethylamphetamine was used to evaluate its corresponding vapor pressure. All correlation coefficients $\left(\mathrm{r}^{2}\right)$ exceeded 0.9968 over this temperature range. Table 6 illustrates the correlation performed at $T=298.15 \mathrm{~K}$.

Table 6. Correlations of $\ln \left(p / p^{\circ}\right)$ vs $\ln \left(t_{\mathrm{o}} / t_{\mathrm{r}}\right)$ at $T=298.15 \mathrm{~K}$.

\begin{tabular}{|c|c|c|c|c|c|c|}
\hline & $\ln \left(t_{o} / t_{r}\right)$ & $\ln \left(p / p^{0}\right)$ & $\ln \left(p / p^{0}\right)$ & $p / \mathbf{P a}$ & $p / \mathrm{Pa} / \mathrm{Lit}$ & Lit. \\
\hline$N, N$-Di-n-butylamine & -7.739 & -5.810 & $-5.83 \pm 0.49$ & $300 \pm 120$ & 304 & [16] \\
\hline$N, N$-Di-n-pentylamine & -9.634 & -7.992 & $-7.90 \pm 0.53$ & $37 \pm 20$ & 34 & [18] \\
\hline$N$-Ethylamphetamine & -10.235 & & $-8.56 \pm 0.54$ & $19 \pm 11$ & $8.2^{1}$ & [21] \\
\hline$N, N$-Di-n-hexylamine & -11.517 & -9.760 & $-9.97 \pm 0.58$ & $4.7 \pm 2$ & 5.8 & [18] \\
\hline 4-Benzylpiperidine & -12.427 & -11.130 & $-10.97 \pm 0.60$ & $1.8 \pm 1$ & 1.5 & [8] \\
\hline$N, N$-Di-n-heptylamine & -13.369 & -11.973 & $-12.00 \pm 0.62$ & $0.62 \pm 0.4$ & 0.64 & [18] \\
\hline \multicolumn{5}{|c|}{$\ln \left(p / p^{o}\right)=(1.096 \pm 0.036) \cdot \ln \left(t_{0} / t_{r}\right)+(2.616 \pm 0.40)$} & \multicolumn{2}{|c|}{$\mathrm{r}^{2}=0.9968(7)$} \\
\hline
\end{tabular}

\section{${ }^{1}$ Estimate.}

The resulting values of $\ln \left(p / p^{\circ}\right)$ as a function of temperature were then fit to a second order polynomial, Equation (8). The resulting constants of Equation (8) are provided in Table 7.

$$
\ln \left(p / p^{\mathrm{o}}\right)=\mathrm{A}_{\mathrm{S}}+\mathrm{B}_{\mathrm{S}}(T / K)+\mathrm{C}_{\mathrm{S}}(T / K)^{2} ; p^{\mathrm{o}}=101,325 \mathrm{~Pa}
$$

\subsection{Estimation of Boiling Temperatures and Their Uncertainties}

Boiling temperatures were evaluated by extrapolating Equation (8) until $\ln \left(p / p^{\circ}\right)=0$. Uncertainties in boiling temperature were evaluated by combining each vapor pressure evaluated from $T=(298.15$ to 450$) \mathrm{K}$ with its respective uncertainty, $p_{\mathrm{u}}(1 \sigma)$, and fitting the results in the form $\ln \left(\left(p+p_{\mathrm{u}}\right) / p^{\mathrm{o}}\right)$ to a second polynomial. Solving for temperature at which this term equaled zero, the uncertainty in boiling temperature was evaluated as the difference between the two temperatures evaluated. 
Table 7. Coefficients of the second order polynomial, Equation (8); $p^{\mathrm{o}}=101,325 \mathrm{~Pa}$.

\begin{tabular}{cccccc}
\hline & $\mathbf{A}_{\mathbf{S}}$ & $\mathbf{B}_{\mathbf{s}}$ & $\mathbf{C}_{\mathbf{s}}$ & $\mathbf{T}_{\mathbf{B}} / \mathbf{K}$ & $\mathbf{T}_{\mathbf{B}} \mathbf{\text { Lit}} / \mathbf{K}$ \\
\hline N,N-Di-n-butylamine & $9.483 \pm 0.02$ & $-3128.7 \pm 12$ & $-427980 \pm 2190$ & $434 \pm 5$ & $432.8^{1}$ \\
N,N-Di-n-pentylamine & $9.395 \pm 0.03$ & $-3271.1 \pm 19$ & $-562,260 \pm 3409$ & $474 \pm 3$ & $475.2^{1}$ \\
N-Ethylamphetamine & $8.347 \pm 0.01$ & $-2872.4 \pm 3.7$ & $-646650 \pm 665$ & $499 \pm 3$ & $508^{2}$ \\
N,N-Di-n-hexylamine & $9.483 \pm 0.04$ & $-3128.7 \pm 27$ & $-427,980 \pm 4919$ & $512 \pm 2$ & $506-516^{1}$ \\
4-Benzylpiperidine & $7.429 \pm 0.01$ & $-2679.1 \pm 10$ & $-836,480 \pm 1734$ & $561 \pm 1$ & $552^{3}$ \\
N,N-Di-n-heptylamine & $9.309 \pm 0.05$ & $-3582.1 \pm 36$ & $-825,650 \pm 6424$ & $547 \pm 1$ & $544.2^{1}$ \\
\hline
\end{tabular}

${ }^{1}$ Reference [8]. ${ }^{2}$ Estimate, reference [21]. ${ }^{3}$ Reference [22].

\section{Discussion}

\subsection{Vaporization Enthalpy}

The results of two correlations used evaluate the vaporization enthalpy of $\mathrm{N}$ ethylamphetamine are summarized in Table 5. The value of $62.4 \pm 4.4 \mathrm{~kJ} \cdot \mathrm{mol}^{-1}$ is in close agreement with the value $(63.5 \pm 3.8) \mathrm{kJ} \cdot \mathrm{mol}^{-1}$, estimated using Equation (2). For comparison, the vaporization enthalpy of $S(+)$-methamphetamine has been reported as $(58.7 \pm 4.3) \mathrm{kJ} \cdot \mathrm{mol}^{-1}$. The difference of $(3.7 \pm 5.8) \mathrm{kJ} \cdot \mathrm{mol}^{-1}$ is within the typical increment in vaporization enthalpy observed for the insertion of a methylene group. Values as small as $(0.9 \pm 1.0) \mathrm{kJ} \cdot \mathrm{mol}^{-1}$ have been observed between liquid ethyl and methyl $p$ aminobenzoate $[23,24]$ and as large as $(5.004 \pm 0.008) \mathrm{kJ} \cdot \mathrm{mol}^{-1} / \mathrm{CH}_{2}$ group in vaporization enthalpy going from pentane to octatriacontane [25].

\subsection{Vapor pressure}

Vapor pressure results for N-ethylamphetamine are reported in Tables 6 and 7. A vapor pressure of $(19 \pm 11)$ Pa compares to a value of $38 \mathrm{~Pa}$ evaluated for $\mathrm{S}(+)$-methamphetamine at $T=298.15 \mathrm{~K}$. Similarly, estimated boiling temperatures at $p=101,325 \mathrm{~Pa}$ of $T=(490$ [8], 489 [21]) $\mathrm{K}$ for $\mathrm{S}(+)$-methamphetamine compare to a corresponding estimated temperature of $T=(499 \pm 3$ (this work), 508 [21]) K. Additionally, several experimental boiling temperatures at reduced pressures have been reported for $N$-ethylamphetamine. Figure 2 provides a qualitative comparison of these values to the values evaluated in this work. The solid circles represent experimental boiling temperatures at reduced pressures while the remainder are estimated values. A numerical comparison of the vapor pressures of $N$-ethylamphetamine to $S(+)$-methamphetamine over the temperature range $T=298,15$ to $T_{\mathrm{B}}$. the normal boiling temperature, is provided as Table S5 (Supplementary Materials).

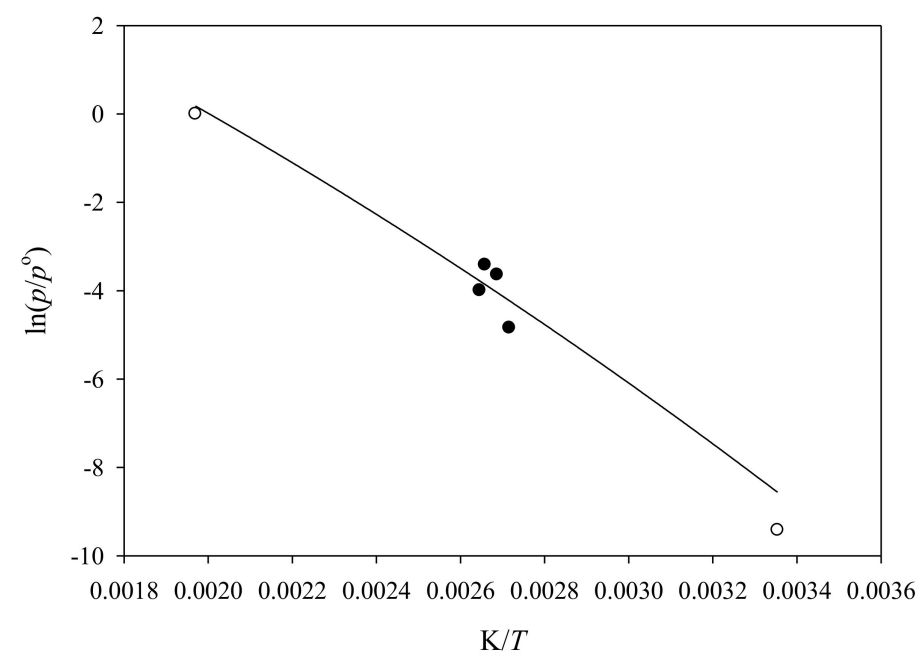

Figure 2. Line: a plot of $\ln \left(p / p^{\mathrm{o}}\right)$ vs. $\mathrm{K} / \mathrm{T}$ of $\mathrm{N}$-ethylamphetamine from $T=(298.15$ to 500$) \mathrm{K}$; $\bullet$ experimental boiling temperatures at reduced pressures (most volatile to least volatile [26-29]; o: estimated values [21]. 


\section{Summary}

Table 8 summarizes the vaporization enthalpy, vapor pressure, the constants of Equation (8) that can be used to predict the vapor pressures of N-ethylamphetamine as a function of temperature and the predicted boiling temperature at $p^{\circ}=101,325 \mathrm{~Pa}$.

Table 8. A Summary of the Vaporization Enthalpy, Vapor Pressure at 298.15 K, Coefficients of Equation (8) and Predicted Boiling temperature at po $=101,325 \mathrm{~Pa}$ of N-Ethylamphetamine.

\begin{tabular}{cccccc}
\hline$\Delta_{l}^{g} \boldsymbol{H}_{\boldsymbol{m}}(298 \mathbf{K}) / \mathbf{k J} \cdot \mathbf{m o l}^{-1}$ & $p / \mathbf{P a}$ & $A_{S}$ & $\boldsymbol{B}_{\boldsymbol{s}}$ & $C_{s}$ & $\boldsymbol{T}_{\mathbf{B}} / \mathbf{K}$ \\
\hline $62.4 \pm 4.4$ & $19 \pm 11$ & $8.347 \pm 0.01$ & $-2,872.4 \pm 3.7$ & $-646650 \pm 665$ & $499 \pm 3$ \\
\hline
\end{tabular}

Supplementary Materials: The following are available online. Tables S1 and S3: Retention times of $\mathrm{N}$ Ethylamphetamine and Standards; Tables S2 and S4: Correlations of $\Delta_{t r n}^{g} H_{m}\left(T_{m} \mathrm{~K}\right)$ with $\Delta_{l}^{g} H_{m}(298 \mathrm{~K})$ of the Standards; Table S5: A Comparison of the Vapor Pressures of (S) (+)-Methamphetamine to $N$-Ethylamphetamine as a Function of Temperature.

Funding: This research received no external funding.

Conflicts of Interest: The authors declare no conflict of interest.

\section{References}

1. National Library of Medicine. Available online: https://pubchem.ncbi.nlm.nih.gov/compound/Etilamfetamine (accessed on 17 March 2021).

2. Cayman Chemical. Available online: https://www.caymanchem.com/product/11557/n-ethylamphetamine-(hydrochloride) (accessed on 17 March 2021).

3. Fitzgerald, R.L.; Ramos, J.M., Jr.; Bogema, S.C.; Poklis, A. Resolution of Methamphetamine Stereoisomers in Urine Drug Testing: Urinary Excretion of $R(-)$-Methamphetamine Following Use of Nasal Inhalers. J. Anal. Toxicol. 1988, 12, 255-259. [CrossRef] [PubMed]

4. Beckett, A.H.; Brookes, L.G.; Shenoy, E.V.B. Urinary excretion of the drug and its main metabolite in man, after the administration of $( \pm)-,(+)$ - and (-)-ethylamphetamine. J. Pharm. Pharm. 2011, 21, 151S-156S. [CrossRef]

5. Orf, M.; Kurian, M.; Espinosa, L.; Nelson, C.; Simmons, D.; Chickos, J. Thermochemical properties of sesquiterpenes in natural products by correlation gas chromatography: Application to bergamotene oil. J. Chem. Thermodyn. 2018, 126, 128-136. [CrossRef]

6. Siripoltangman, N.; Chickos, J. Vapor Pressure and vaporization enthalpy studies of the major components of ginger, $\alpha$ zingiberene, $\beta$-sesquiphellandrene and $(-)$ ar curcumene by correlation gas chromatography. J. Chem. 2019, 138, 107-115. [CrossRef]

7. Zafar, A.; Chickos, J. The vapor pressure and vaporization enthalpy of squalene and squalene by correlation gas chromatography. J. Chem. Thermodyn. 2019, 135, 192-197. [CrossRef]

8. Thornton, M.; Gobble, C.; Chickos, J. The vaporization enthalpy and vapor pressure of S (+)-methamphetamine at $T=298.15 \mathrm{~K}$ by correlation gas chromatography. J. Chem. Thermodyn. 2014, 73, 51-56. [CrossRef]

9. Peacock, A.; Fuchs, R. Enthalpy of vaporization measurements by gas chromatography. J. Am. Chem. Soc. 1977, 99, 5524-5525. [CrossRef]

10. Chickos, J.S.; Hanshaw, W. Vapor pressures and vaporization enthalpies of the n-alkanes from $C_{21}-C_{30}$ at $T=298.15$ by correlationgas chromatography. J. Chem. Eng. Data 2004, 49, 77-85. [CrossRef]

11. Nichols, G.; Kweskin, S.; Frericks, M.; Reiter, S.; Wang, G.; Orf, J.; Carvallo, B.; Hillesheim-Cox, D.; Chickos, J.S. An Evaluation of the The Vaporization, Fusion and Sublimation Enthalpies of the 1-Alkanols. The Vaporization Enthalpy of 1-, 6-, 7-, and 9-Heptadecanol, 1-Octadecanol, 1-Eicosanol, 1-Docosanol, 1-Hexacosanol and Cholesterol at $T=298.15 \mathrm{~K}$ by Correlation-Gas Chromatography. J. Chem. Eng. Data 2006, 51, 475-482. [CrossRef]

12. Guide to the Expression of Uncertainty in Measurement BIPM. Available online: http://www.bipm.org/en/publications/guides / gum.html (accessed on 17 March 2021).

13. Roux, M.V.; Temprado, M.; Chickos, J.S. Vaporization, fusion and sublimation enthalpies of the dicarboxylic acids from $\mathrm{C}_{4}$ to $\mathrm{C}_{14}$ and $\mathrm{C}_{16}$. J. Chem. Thermodyn. 2005, 37, 941-953. [CrossRef]

14. Chickos, J.S. Computational Thermochemistry: Prediction and Estimation of Molecular Thermodynamics; Irikura, K.K., Frurip, D.J., Eds.; ACS Symposium Series 677; American Chemical Society: Washington, DC, USA, 1996; Chapter 4; pp. 77-79.

15. Acree, W., Jr.; Chickos, J.S. Phase Transition Enthalpy Measurements of Organic and Organometallic Compounds. Sublimation, Vaporization and Fusion Enthalpies From 1880 to Part C1-C10. J. Phys. Chem. Ref. Data 2016, 45, 1-565. [CrossRef]

16. Petros, L.; Majer, V.; Koubek, J.; Svoboda, V.; Pick, J. Temperature Dependence of Heats of Vaporization, Saturated Vapour Pressures and Cohesive Energies of Secondary Amines. Coll. Czechoslov. Chem. Commun. 1979, 44, 3533-3549. [CrossRef]

17. Wadso, I. Enthalpies of Vaporization of Organic Compounds. III. Amines. Acta Chem. Scand. 1969, 23, 2061. [CrossRef] 
18. Stephenson, R.; Malanowski, S. Handbook of the Thermodynamics of Organic Compounds; Springer Science \& Business Media: Berlin/Heidelberg, Germany, 1987. [CrossRef]

19. Ribeiro da Silva, M.A.V.; Cabral, J.I.T.A. Thermochemical Properties of Three Piperidine Derivatives1-Benzyl-4-piperidinol, 4-benzylpiperidine and 4-piperidine-piperidine. J. Therm. Anal. Calorim. 2007, 90, 865-871. [CrossRef]

20. Zabransky, M.; Ruzicka, V., Jr.; Majer, V.; Domalski, E.S. Heat Capacity of Liquids: Critical Review and Recommended Values. Vol. I and II. J. Phys. Chem. Ref. Data 2001, 30, 1199. [CrossRef]

21. EPI Suite Version 4.11 (Estimation Programs Interface). Available online: http://www.epa.gov/oppt/exposure/pubs/episuitedl. htm (accessed on 8 April 2021).

22. Aldrich Handbook of Fine Chemicals (2012-2014); Sigma Aldrich: St. Louis, MO, USA, 2012.

23. Ledo, J.M.; Flores, H.; Freitas, V.L.S.; Solano-Altamirano, J.M.; Hernández-Pérez, J.M.; Camarillo, E.A.; Ramos, F.; Ribeiro da Silva, M.D.M.C. Benzocaine: A comprehensive thermochemical study. J. Chem. Thermodyn. 2020, 147, 1-8. [CrossRef]

24. Almeida, A.R.R.P.; Monte, M.J.S. Thermodynamic study of phase transitions in methyl esters of ortho- meta-and para-aminobenzoic acids. J. Chem. Thermodyn. 2012, 53, 100-107. [CrossRef]

25. Chickos, J.S.; Hanshaw, W. Vapor Pressures and Vaporization Enthalpies of the $n$-Alkanes from $C_{31}$ to $C_{38}$ at $T=298.15 \mathrm{~K}$ by Correlation Gas Chromatography. J. Chem. Eng. Data 2004, 49, 620-630. [CrossRef]

26. Temmler, T.H.; Keil, F.; Dobke, W. $\beta$-Aralkylamines. DE 767263; SciFinder Scholar; Chemical Abstracts Service: Columbus, OH, USA, 1952.

27. Shiho, D.; Kanayama, K. A new process of alkylation of amines. II. Nippon Kagaku Kaishi 1944, 65, 237-239. [CrossRef]

28. Leonard, N.J.; Adamcik, J.A.; Djerassi, C.; Halpern, O. Cyclic amino acyloins and amino ketones. X. Trans-annular nitrogencarbonyl interaction in cyclic aminoketones and optical rotatory dispersión. J. Am. Chem. Soc. 1958, 80, 4858-4862. [CrossRef]

29. Chiavarelli, S.; Marini-Bettolo, G.B. Synthetic sympatholytic substances in the ergotamine series. II. Derivatives of benzylamine, phenethylamine, and $\alpha$-methylphenethylamines with amine and amide functions. Gazz. Chim. Ital. 1951, 81, 89-97. 